\title{
DESCRIÇÃO DA MULHER. POR UMA FILOSOFIA DE OUTREM SEXUADA.
}

Por Gilles Deleuze

Para Alain Clément.

A mulher ainda não tem estatuto filosófico. Problema urgente. As filosofias do Outrem são estranhas; com elas, não se fica à vontade. E por uma razão bem simples: o mundo que se nos propõe é um mundo assexuado. Reciprocidades, comunicações, comunhões, essas conscienciosas misturas são a obra muito pura das almas. Essa insuficiência das filosofias do Outrem, o Sr. Sartre parecia ter notado quando censurava Heidegger por ter deixado assexuada a "realidade humana" ao desejo e outro ao amor. Mas o progresso é apenas aparente. O que é sexuado, então, é aquele que faz amor, é o amante, e de maneira alguma o amado. O amado é em si mesmo sexuado apenas na medida em que é, por sua vez, amante. Reencontra-se a ilusão clássica de uma reciprocidade das consciências: Outrem seria simplesmente outro EU, tendo suas próprias estruturas apenas no sentido em que é sujeito. Isso é dissolver o problema do Outrem. Como se apenas o amante fosse sexuado, como se fosse o amante que conferisse ao amado o sexo oposto, mais que isso: como se o amor habitual e a pederastia não diferissem essencialmente. Visão contrária a toda descrição sincera, na qual é o outro enquanto tal, e não como outro EU, que se revela em seu sexo, que é objetivamente amável e que se impõe ao amante. A fenomenologia deve ser aquela do amado. Por isso, o mundo de Sartre é ainda mais desolador que o outro: um mundo objetivamente de assexuados, mas com os quais só se pensa em fazer amor, um mundo completamente monstruoso.

Grande princípio: as coisas não esperaram por mim para ter sua significação. Ou, pelo menos, o que do ponto de vista descritivo vem a dar no mesmo, eu não tenho consciência de que elas tenham me esperado. A significação se inscreve objetivamente na coisa: há o fatigante, por exemplo, e isso é tudo. Esse grande sol redondo, essa estrada que se

1 Originalmente publicado na revista Poésie 45, no 28, oct-nov. 1945, p.28-39. Esse é um dos quatro textos expressamente renegados por Deleuze, publicados entre 1945 e 1947 e que não estavam autorizados para publicação na França até recentemente, quando foram incluídos na coletânea editada por David Lapoujade: Gilles Deleuze, lettres et autres textes (Minuit, 2015). Quanto à tradução, ela foi feita a partir de uma cópia do texto original, gentilmente fornecida para nós por Luiz B. L. Orlandi que, por sua vez, a recebeu das mãos de Éric Alliez. Consultada por nós, circulou por alguns anos uma tradução, disponibilizada em um xerox na PUC-SP, pelo próprio Orlandi, feita pelo seu aluno A. T., a quem reputamos como precursor da presente tradução, lamentando que ele tenha assinado a sua versão apenas com as iniciais. Nota dos tradutores (NT): Juliana Oliva e Sandro K. Fornazari.

20 ser e o nada. 
estende, essa fadiga na cavidade dos rins. Eu não sou responsável por nada disso. ${ }^{3}$ Não sou eu que estou fatigado. Eu nada invento, nada projeto, nada faço vir ao mundo, eu nada sou, nem mesmo um nada, não sobretudo: nada senão uma expressão. Eu não penduro nas coisas minhas pequenas significações. O objeto não tem uma significação, ele é sua significação: o fatigante. Ora, esse mundo estritamente objetivo, esse mundo sem sujeito encerra em si mesmo o princípio da sua própria negação, de sua própria nadificação: um objeto dentre os outros, mas que não tem menos especificidade, o mais objeto dos objetos que se chama Outrem. Outrem está nesse mundo fatigante e, no entanto, por sua atitude e por todos os seus gestos, seu passo ágil, sua respiração calma e sua desenvoltura, ele pode exprimir um mundo no qual não há o fatigante. Outrem é isso: " $a$ expressão de um mundo possivel"' . A expressão de um mundo exterior ausente, um expressante sem expressado. O mundo expressado por Outrem, o universo inteiro que é Outrem, se inscreve nessa categoria de objetos da qual Valéry falava: "ação de presença de coisas ausentes". Ação de presença ao revés, mas que é suficiente para rechaçar em mim o universo antigo, para me enfiá-lo na garganta, para me fazer tomar consciência de que, desta vez, sou eu mesmo que estou fatigado. Transformação mágica do fatigante em fatigado. Sou eu, apenas eu: responsabilidade grande demais, ela é insuportável, idêntica à contingência. Tenho vergonha. Essa vergonha, essa tomada de consciência que destrói toda descrição objetiva e serena, essa consciência de Outrem, é a timidez, o ódio dissimulado a respeito de outrem. Mas, Outrem é somente o inimigo, o odioso? Ele não é nada senão a expressão de um mundo exterior possível? Ele não é também a oferta de uma amizade? Eu superarei minha fadiga, eu farei do sol e da estrada e da própria fadiga encorajamentos, eu me sacrificarei sem reciprocidade; eu sacrificarei essa fadiga tornada minha, tornada eu, que me era tão cara, eu realizarei enfim esse mundo exterior ausente que Outrem me revela, em uma palavra, eu me associarei a Outrem... Visão otimista: a que preço ela se verificará? E relativamente ao autêntico, qual é o sentido respectivo do ódio e da amizade? Está aí todo o problema do Outrem. E não é nosso problema; nós falamos dele somente na medida em que a descrição da mulher não pode se fazer sem referência ao Outrem-macho.

Eis o Outrem-macho, definido não como uma consciência, não como outro EU, mas objetivamente como uma exterioridade possível. Completamente outra é a mulher. Aqui, é preciso ser simplista, ater-se à imagem ingênua: a mulher maquiada que atormenta o

\footnotetext{
3 [Nesse ponto, com esse exemplo, Deleuze muito provavelmente está se referindo ao romance de A. Camus, $O$ estrangeiro, especialmente às suas páginas iniciais que descrevem o velório e o cortejo fúnebre da mãe do protagonista. A primeira edição de O estrangeiro é de 1942 (NT)].

4 Eu tomo emprestada essa expressão de um texto inédito de Michel Tournier.
} 
adolescente tenro, misógino e dissimulado. Sobre o rosto dessa mulher, procurar-se-ia em vão a expressão de um mundo exterior ausente. Nela tudo é presença. A mulher não exprime nenhum mundo possível; ou melhor, o possível que ela exprime não é um mundo exterior, é ela mesma. A mulher não exprime senão ela mesma: autoexpressão, inocência, serenidade. Também se pode dizê-la intermediária entre o objeto puro, que nada exprime, e o Outrem-macho, que exprime outra coisa que ele, um mundo exterior. A mulher nos faz presenciar a gênese de Outrem, nascido do objeto, na passagem do objeto a Outrem. Por outro lado, pode-se distingui-la nitidamente do Outrem-macho: eu posso, aos meus próprios olhos, ridicularizar Outrem, insultá-lo gravemente, negar a possibilidade do mundo que ele exprime, isto é, reduzir Outrem a um puro comportamento mecânico absurdo. Com efeito, chama-se "comportamento" a própria expressão, cortada do mundo exterior possível que ela desenha ao revés, que ela exprime pela ausência. O comportamento é o expressante cortado do expressado; é verdade que, no caso do Outrem-macho, o expressado está ausente, mas ele não é menos isso em direção ao qual o expressante tende completamente. Fechado sobre si mesmo, cortado de sua superação, Outrem toma uma aparência absurda, se reduz a gestos incoerentes. A mulher, ao contrário, em sua enorme presença, impossível de negá-la, de insultá-la: impossível de fazer o corte. Então, não há mundo exterior; o expressado é o expressante. A mulher se dá em um bloco indecomponível, ela surge e nela o interior é exterior, o exterior é interior. A coincidência do expressante e do expressado é a consciência. Consciência definida de fora, objetivamente, mas, enquanto tal, muito particular: ela não é em situação, consciência pura que exprime a si mesma, consciência de si e não de alguma coisa. Toda a carne da mulher é consciente, toda sua consciência é carne. A mulher é seu próprio possível, ela se possibiliza.

Tal é seu mistério, sua graça. O que não se percebeu o suficiente é que a graça se define por uma mistura de peso e de leveza, tal que o peso é o mais leve, e a leveza, a mais pesada. O corpo da mulher é o triunfo transbordante da carne, da materialidade: "Uma barriga delicada que se via apesar do vestido em volta das coisas comuns das mulheres: as pernas, os braços, o que resta; mas, sobretudo, uma barriga delicada. Um sol vos fazia fervilhar o sangue e depois ainda duas luzes espessas sobre seu corpo, os seios e, acima, esse rosto onde ela trazia sua boca espessa sempre fechada - oh, prudência! - e seus olhos que cantavam todo o tempo como os belos verdilhões"'. A mulher é essencialmente a encarnada; mas, quanto mais ela se enfia na materialidade, mais ela se faz imaterial, mais se refaz através da expressão de si mesma, tornando-se o próprio possível do ser que ela é. Enquanto coisa, ela é consciente, e enquanto consciente, ela é coisa. Ela é indissoluvelmente possibilidade de ser e ser do possível, carne do possível: dito de outra maneira, leveza do peso e peso da leveza. É a graça, essa união dos contrários, uma estrita identi-

5 Giono, O canto do mundo, p. 120. 
dade do material e do imaterial. Consciência do seu próprio peso, do seu enfiamento no mundo. (Entendamos: não se trata de lastimar sob seu peso, não é isso, ter consciência não é sofrer seu peso como uma significação, "pesada demais, não o suficiente...”, trata-se de uma consciência pura). Barriga delicada, como diz Giono: a consciência é delicadeza. E o perigo que pesa sobre a mulher como um peso sem graça é que ela a perca, essa consciência, que ela não seja mais que uma barriga, uma materialidade transbordante, uma suculenta maquiagem: então ela é uma coisa. Não falemos disso, é penoso demais: uma mulher que perde seu ser. Porque seu ser é essa incrível unidade de consciência e de carne. A mulher é uma consciência e, contudo, nada exprime de exterior a si mesma. Ela é uma consciência inútil. Uma consciência gratuita, autóctone, indisponível. Ela não serve para nada. Um objeto de luxo.

O próprio dos objetos de luxo é que eles não servem para grande coisa. Ora, há duas maneiras de ser inútil. Primeiro, objeto tão preciso, tão minucioso, tão precioso que não tem mais aplicação, objeto supérfluo tão diretamente se dirigindo ao seu possuidor que este não pode se basear nele para agir: com efeito, o eu que age é sempre substituível, sempre mais ou menos qualquer pessoa, jamais é único. Para além do eu que age, o objeto de luxo se dirige a um eu mais profundo, mais interior, mais feminino, por exemplo, um eu que se regozija ao ver, exibidas num cigarro, suas inúteis iniciais. Objeto de luxo do qual se serve um ser de luxo: ser tão geral, neste caso, tão vasto que todo uso é especial demais. Nesse sentido, a mulher é cósmica. Ela é coisa e consciência, coisa na consciência, consciência na coisa. E a pura consciência, a consciência de si leva a matéria que ela afeta ao coeficiente cósmico, a torção em um retorno sobre si. A consciência da mulher não se abre para uma pluralidade de mundos exteriores ausentes, ela se fecha sobre a matéria que ela possibiliza, que ela universaliza. A mulher é um universal concreto, ela é um mundo, não um mundo exterior, mas o debaixo do mundo, a morna interioridade do mundo, um comprimido de mundo interiorizado. De onde o prodigioso sucesso sexual da mulher: possuir a mulher é possuir o mundo. Essa síntese do ser e do possível é o que se chama a "necessidade" da mulher.

Consequência moral: da mulher jamais se fará uma amiga. Que nossos garotos e nossas garotas renunciem a essas teorias hipócritas. A amizade é a realização do mundo exterior possível que nos oferece Outrem-macho. A mulher não tem mundo exterior a nos propor. A mulher não é quem pode negar violentamente, numa proposição irretocável, esse mundo que há pouco eu acreditava objetivo, esse mundo fatigante, por exemplo, substituindo-o por outro mundo, onde não há o fatigante. Ela é simplesmente, em sua essência, aquilo que tem o poder de me desinteressar do resto das coisas, porque ela mesma 
é uma coisa sem relação com as outras, porque ela é um mundo sem exterioridade. É isso que se exprime quando se diz: esta mulher é desejável.

Que haja contrariedade profunda entre o amigo e o amado, isso é um fato bem conhecido. "Esta mulher é desejável”, não sou eu quem projeta sobre ela essa significação (que nos lembremos do grande princípio), não sou eu quem a deseja, ela me aparece como desejável. Mas no próprio cerne desse mundo centrado em torno dela, meu amigo pode contrariamente achá-la desprezível e feia: revelação de um mundo possível onde ela não é amável. Conflito célebre entre o amor e a amizade. Eu vou realizar esse mundo exterior possível que Outrem me revela?... A mulher sente esse conflito, de modo que de duas coisas, uma, ou ela vai tentar me indispor com meu amigo, ou ela vai seduzi-lo, impor-lhe a expressão de um mundo onde ela é desejável, reduzi-lo à existência surda junto a mim de um rival: rival do qual eu sou ciumento, não mais o amigo, ele, que apenas existe na oposição dos mundos. - Tudo isto, pretexto para inumeráveis romances.

Retenhamos portanto essa oposição da mulher e do Outrem-macho. Entretanto, não pode a mulher exprimir um mundo exterior possível? Não pode ela, como Outrem-macho, propor um mundo fatigante, não fatigante, etc.? De uma vez por todas: esse não é o papel da mulher, nele ela perde sua essência. $O$ homem que sente prazer em ver a mulher exprimir um mundo exterior, eu o chamo sádico. (Das formas inofensivas do sadismo até as formas mais sutis, mais evoluídas, nas quais se impõe à mulher uma máscara de sofrimento e de medo, expressão de um mundo doloroso). Um único exemplo: a ruga no Outrem-macho, o rosto surpreendido, que se enruga para ver melhor e para compreender, exprime um mundo possível, uma resistência exterior a penetrar: rugas largas, longas, bem desenhadas, separadas por refegos iguais, abastança de rugas, em um rosto feito para isso. Oh, a ruga no rosto de uma mulher, ao contrário! Mil fendazinhas em desordem e tão desajeitadas, elas são curtas, renunciam rapidamente, recomeçam em outra parte, um pouco abaixo, sem sucesso, cortes movediços de canivete ou papel amarrotado; de fazer chorar, a impotência do rosto para se contorcer de modo coerente é ridícula e tocante. (Ridículo e tocante: curiosa aliança de palavras, que retornam sempre ao espírito). O sádico disse à mulher: senta aí e franze sua testa.

Diabo no corpo. Dir-se-ia que elas querem uma filosofia de Outrem assexuada. São as próprias mulheres que correm para sua perda, elas querem exprimir um mundo exterior, todos os mundos exteriores possíveis, içar-se ao nível do Outrem-macho, ultrapassá-lo. Nisso, elas perderão sua essência. Um duplo perigo pesa sobre a mulher, independentemente aliás de toda questão de idade: "velhas" demais, elas se reduzem a uma coisa inexpressiva; "jovens" demais, elas querem fazer como Outrem-macho. Mais uma vez ainda, é preciso ser simplista: seu lugar não é no exterior, é na casa, no interior. Vida do interior e vida interior: a palavra é a mesma. 
A mulher é seu próprio possível: ela exprime não um mundo exterior, mas o mundo interior. Ou melhor, a vida interior é essa identidade do material e do imaterial, que faz a própria essência da mulher. Enquanto Outrem-macho se define antes de tudo pela exterioridade, a mulher é uma interioridade enorme, quente, viva:

A maquiagem é a formação dessa interioridade. Nós vimos como a consciência de si imaterializa, interioriza a matéria que ela afeta. E não esqueçamos que essa consciência, nós a definimos sempre de fora. Deste ponto de vista, a maquiagem não aparecerá como uma máscara, colocada sobre um rosto para revestir-lhe a expressão, mas como a própria Pessoa feminina, instaurando uma ordem sobrenatural, isto é, interiorizando a natureza. Num livro de título promissor e que não mantém suas promessas ${ }^{6}$, Billy se refere a "esse acordo de certa forma consubstancial da carne e da pintura", "não sei que acordo da carne com a civilização". Nós sabemos agora que o que mantém esse acordo entre a natureza e a Pessoa é o próprio ato de interiorizar a natureza sob a forma de Pessoa, é a consciência. Ela se localiza, essa consciência, essencialmente no pescoço, nos tornozelos, há lugares de graça: os tornozelos, ou melhor, os sapatos de salto alto, consciência do peso do corpo, e o pescoço, consciência do peso da cabeça. No Outrem-macho, ao contrário, o pescoço jamais é consciência.

Distinguem-se dois tipos de maquiagem. Primeiro, a maquiagem das superfícies, à base de pasta e de pó, que consiste em deixar a superfície absolutamente lisa, "insignificante" no sentido etimológico, inexpressiva, para preservá-la de toda situação, de toda marca de exterioridade (rugas, cicatrizes, etc.). A maquiagem dos orifícios, por outro lado, consiste assim em salientar toda interioridade ${ }^{7}$. Ora o exterior se interioriza: o preto que contorna o olho arromba o olhar, torna-o interior a si mesmo. Ora o interior se exterioriza, mas conservando, para além da sua exteriorização, o seu ser interior: os lábios avermelhados são a irrupção de uma interioridade espessa, e esse vermelho dir-se-ia que ele se prolonga ao interior, vermelho como ele é, vermelho sempre mais distante, sob a pele, sob a superfície que ele tinge de rosa; assim a maquiagem dos orifícios se apodera até mesmo das superfícies. E não apenas os lábios, mas também as unhas: aqui ainda o vermelho se prolonga, se prolonga tão bem que se perde o hábito absurdo de deixar a lúnula em branco.

O problema das sobrancelhas se coloca, ao mesmo tempo em que o da junção das duas maquiagens. Na mulher, o cabelo marca uma proliferação, uma exuberância interna, uma fecundidade interior inesgotável. Mas, não é esse, mais ou menos, o sentido do pelo

6 A mulher maquiada, p.78 [trata-se de um romance de André Billy (Flammarion, 1932) (NT)].

7 [Aqui, corrigimos do texto original o que acreditamos ser um erro tipográfico, substituindo "infériorité" por "intériorité" (NT)]. 
em geral? Então, por que a mulher depila as suas sobrancelhas? É que, apesar de todas as aparências, as sobrancelhas são a marca de uma exterioridade, ou melhor, a marca de uma fronteira entre o interior e o exterior: abaixo das sobrancelhas está a interioridade dos olhos, acima, a exterioridade da testa. Mas a mulher suprime toda fronteira entre interior e exterior, ela busca reduzir o exterior ao interior o máximo possível, para assegurar a primazia do interior, daí, supressão das sobrancelhas. Pela depilação, faz-se a junção das duas maquiagens.

Outros signos de uma proliferação interna: a pinta. As sardas: "Não as imagino como um defeito. Elas parecem sua tez. Sua pele parecia ser de uma essência mais rara. Como ocorre com as madeiras preciosas. Desde que eu, mais de uma vez, sem me dar conta, tive de procurar sobre os belos rostos essas sardas e ficar um pouco decepcionado com sua ausência"8. Eu realmente não compreendo por que a mulher tem vergonha das sardas e as combate por meio da maquiagem e, ao contrário, cultiva, ou ao menos por muito tempo cultivou, a pinta. Isso só pode se explicar por um erro da mulher sobre sua própria essência. As sardas evocam um impulso misterioso e perfeito, uma trajetória ágil procedente de qual estilingue? Assim como as bolhas vindas de longe, que se desenhariam na superfície e não a inflariam, sem volume e sem estourar. Por mais que passemos a mão, elas não se enroscam, não desalinham, simples desabrochamento em superfície, proliferação sem espessura, charme irritante: vê-se as sardas e não se pode tocá-las, os seus contornos são simplesmente visuais e as próprias sardas estão fora de alcance: impossível pegá-las com dois dedos, contorná-las com o dedo, fazê-las salientes. E, no entanto, elas estão lá, ao meu alcance, não fogem, imutáveis e serenas. A sarda vai ao encontro do reflexo de Narciso ou do suplício de Tântalo: ao meu alcance e fora de alcance. Essa presença indiferente e inexorável, isso que se pode ver e que não se pode tocar, eu chamarei de númeno. O númeno é verdadeiramente o símbolo do interior no exterior e que, para além da sua exterioridade, mantém seu ser do interior. No limite, inclusive, toda a maquiagem tende a se fazer numênica: o que se pode ver e que não se pode tocar. A interioridade é o inviolável. Não desarrumar esse penteado, não tocar essa maquiagem. Defesa verbal proferida pela mulher que, todavia, para além das palavras, revela a verdadeira significação ontológica da maquiagem. Pelo contrário, é preciso desconfiar da pinta, que tem espessura, que se deixa contornar, que não é numênica. E depois a pinta está sozinha, não aparece em grupo, é de um preto pronunciado. Em suma, ela prepara e suscita uma inversão "irônica": em vez de o rosto ter uma pinta, é a pinta que "tem" o rosto, todo o rosto se organiza em torno de uma pinta preta. Efeito desastroso, que as sardas, dada sua multiplicidade, sua primorosa leveza e sua perfeição são incapazes de suscitar.

O segredo é apenas uma interioridade escondida. Situado no cume da vida interior, 
no entanto, este não é o seu aspecto mais interessante: o que pensa a mulher, sobretudo o que a faz rir, e que os homens jamais compreenderão. A timidez diante da mulher, e aquela outra timidez, da qual nós já falamos, que inspira Outrem-macho, são muito diferentes: a mulher não é como Outrem, não revela um mundo novo, simplesmente ela me observa, ela pensa alguma coisa de mim e seus pensamentos a fazem rir. Sou tomado pela confusão por ver-me como o efeito de subentendidos, de interpretações, de segredos que eu não desconfiaria, de cochichos não à minha honra. E minhas tentativas de sedução não eram senão uma vontade de impressionar a mulher, de reduzir sua interpretação a uma pura expressão, a um espelho onde eu me encontrarei tal como eu quero ser, tal como, a rigor, eu creio ser. Noutro pólo, o sadismo é uma sedução violenta, trata-se de destruir na mulher os segredos que ela tem. Daí a destruir o segredo que ela é... Porque, se a mulher, enquanto ela é sujeito, tem segredos, ela é, como objeto, o próprio Segredo e o Subentendido. O segredo é toda uma categoria de coisas - que não se diz em voz alta, que, por natureza, devem ser compreendidas por meias-palavras. Para as crianças, é verdade, não somente uma categoria de coisas, mas tudo, estritamente tudo é segredo: alfabetos secretos, piscadelas, elas se cutucam com os cotovelos, riem a propósito de nada. É o subentendido no estado puro: uma forma sem matéria. E essas mesmas crianças, por outro lado, são absolutamente disponíveis, têm a consciência ingênua, elas refletem, exprimem todos os tipos de coisas que elas nem mesmo procuram interpretar: aqui, matéria sem forma. Contudo, vem a puberdade, é o encontro da forma sem matéria e da matéria sem forma; e isso, a propósito da garota, da mulher. Os adolescentes se cutucam com os cotovelos não mais sem razão, quando uma garota passa. O segredo se encarnou, a forma do segredo se materializou, a matéria se informou. O segredo, por conseguinte, é a Mulher e tudo o que toca a sexualidade. É o escândalo. Daí nasce o complexo da puberdade que, sobre nossa vida inteira, fará pesar a surda influência; a vida provinciana e, de porta em porta, aquilo que se conta em voz baixa.

A mentira é a interioridade preservada, defendida. Sabe-se bem que a mulher mente enormemente. É de fato mentira ou apenas a afirmação de uma verdade feminina? Há dois tipos de mentiras. Por um lado, a vida interior defendida contra todo retorno ofensivo do exterior, as secreções imaginativas para digerir as mais duras exterioridades, a recusa sistemática de toda determinação extrínseca (cf. a Mulher e sua idade). Por outro lado, em vez de entregar sua vida interior ao amante que a reclama, antes de exteriorizá-la, a mulher prefere deformá-la, desfigurá-la, quase sabotá-la: tais são as garantias do amor.

$O$ sonho é a interioridade entregue, que se oferece. É novamente a interioridade essencial, aquela que nós havíamos perdido desde a maquiagem, não mais a interioridade escondida ou preservada de todo alcance exterior, ao contrário, aquela que se espalha, se entrega inteiramente ao exterior, embora, enquanto interior, inviolável. Por que nós a tínhamos perdido? Agora eu sei. O olhar é um dos elementos essenciais da pessoa femi- 
nina, da maquiagem. É ele que nos fez abandonar a essência, que nos impeliu na direção de uma interioridade mental, secundária e derivada - mentira, segredo. Ei-la novamente, aquela essência feminina, e nós vamos compreendê-la melhor - já que agora os olhos estão fechados. Não há mais com o que se preocupar em seduzir; ela dorme. Aquela pura identidade do material e do imaterial, do ser e do possível, ela se declara como um coração que bate, um peito que se eleva compassadamente. A mulher agora está ao meu alcance. Nós vamos encontrar a experiência da maquiagem, ao meu alcance e fora de alcance? Que significa essa interioridade que se dá ao exterior enquanto interior? Refletindo bem, parece que a interioridade como tal não possa jamais aparecer ao exterior, jamais se dar: só se conhece aquilo que esconde o interior e o recobre. De nada me serve, para constituir uma interioridade total, amontoar sobre esse corpo vestes sobre vestes, e muros após muros em torno da casa: o único muro e a única veste que me seja dado para o exterior, por definição, não é interior... Porém, desconfiar das antinomias: elas soam falso. Um gesto simples as destrói. O amontoamento das vestes é apenas uma obstinação ou um mergulho pueril no erro. Jamais a mulher é mais interior a si própria do que quando ela está nua: quando ela dorme e se entrega inteiramente à exterioridade. A essência da vida feminina é mesmo esta: ao meu alcance e fora de alcance. Segredo, mas segredo essencial, nem mental nem carnal: númeno. Tem-se o segredo acidental: tem-se um segredo, protege-se um segredo, constrói-se um muro em torno dele, ao abrigo de toda exterioridade que o faria desaparecer enquanto segredo. Não é segredo senão na medida em que, para Outrem, ele se manifesta como uma ausência a se preencher, alguma coisa a se saber e que não se sabe. Ao contrário, a mulher que dorme é o segredo: não mais um ter segredo, mental, carnal, mas a possibilidade do segredo, o ser do segredo, totalmente exposto na exterioridade e que, para além dessa exterioridade, conserva seu ser de segredo. Um segredo sem matéria e que não se esconde. Aqui não há nada a saber; inviolável, porque não há nada a violar, a não ser um corpo.

E, no entanto, essa interioridade não pode ser desatada, desenlaçada, desfeita? Ao menos pela ação do amante, pela carícia. Renunciar a essa última esperança; a carícia não é aquilo que desfaz, mas aquilo que realiza. Nós falamos amiúde de uma interioridade que se entregava ao exterior como interior. Ou melhor, o interior é a escava da exterioridade, sua torção sobre si mesma. É a negação de uma espessura, uma espessura oca. Vamos portanto mais longe, não somente o segredo sem matéria, sem distinção de forma e de matéria, o segredo do segredo, o segredo de si mesmo, mas, além disso, o segredo sem qualquer espessura: tal é o termo ideal para o qual tende a mulher, jamais atingido. Todavia, nunca mais do que sob a carícia ela se aproxima disso. Não confundir com o 
apalpamento. Com efeito, é a carícia que nega toda espessura, incessantemente ela dobra a exterioridade, faz com que ela se volte sobre si mesma, torna-a interior a si mesma, traçando uma curva delicada e flexível. A carícia exprime essencialmente a síntese do ser e do possível, essa consciência de si que alivia a carne, essa identidade do material e do imaterial, do exterior e do interior. Gesto incansável do escultor amoroso. Ora, se pela carícia como ato, o amante pode se aproximar da essência feminina, é porque a própria mulher é o ser como carícia, o segredo sem espessura. Porém, aqui o ser jamais se realizou, sempre retido mais baixo pelos restos de uma exterioridade infinitamente renascente, que é preciso novamente acariciar. Não há imaterialidade total, pura interioridade sem espessura a recuperar. Além disso, ela seria assaz decepcionante, essa negação total da espessura. Com efeito, que seria ela senão a água, o reflexo? Essa imagem, ela já apareceu para nós: sardas, reflexo de Narciso, númeno - o que se pode ver e não se pode tocar. Mas a mulher aí perderia tudo: a interioridade total realizada no reflexo não teria existência própria, existiria apenas em referência ao refletido. Seria bem perigoso realizar um ideal desenhado sob a forma da ausência, preencher o pontilhado. Dissolver-se-ia a mulher em uma pura interioridade, ela viraria água. $\mathrm{O}$ amante encontraria na pura interioridade o seu reflexo, mas a mulher reduzida ao ser como carícia nela perderia sua substância. Felizmente o ser como carícia é sempre o que se desenha ao revés, guiando as mãos do amante como também guiava as operações da maquiagem; pura ausência que funda a necessidade da carícia como ato. Também a mulher tem necessidade de um amante. Amante que a acaricia, e nada mais. Tal é o verdadeiro estatuto ontológico: o ser da mulher jamais se realizou, não pode se realizar sem contradição, sem dissolução. Seu ser não existe a não ser sob forma de ato efetuado por um outro. A mulher não é nem objeto nem sujeito, ela não é mais somente o que se tem, mas ainda não é o que é, ela é o impulso do objeto em direção à subjetividade. Nem objeto no mundo, nem sujeito de um mundo possível. Ela não é sujeito, não atinge o ser: ser desenhado somente ao revés, ser não realizado - daí um último aspecto da graça, e a razão da necessidade ridícula que um homem sente de proteger a mulher.

A carícia esgota todo o amor? Certamente, ela funda a sua possibilidade. Mas o amor, para além da carícia, coloca um problema completamente outro: impuro. Ele faz parte de uma dinâmica da mulher ou, se preferir, de uma descrição moral. Abandona-se assim o domínio de uma descrição das essências.

Gilles DELEUZE

Tradução de Juliana Oliva ${ }^{9}$ e Sandro K. Fornazari ${ }^{10}$

9 Doutoranda em Filosofia da Universidade Federal de São Paulo.

10 Docente do Departamento de Filosofia da Universidade Federal de São Paulo 